\title{
Educational escape rooms: challenges in aligning game and education
}

Sigrid Merx

Utrecht University, Department of Media and Culture Studies

Muntstraat 2a, 3512 EV Utrecht

s.merx@uu.nl

Alice Veldkamp

Utrecht University, Freudenthal Institute

Buys Ballotgebouw, Princetonplein 5, 3584 CC Utrecht

A.Veldkamp@uu.nl

Jasper van Winden

Utrecht University, Faculty of Science, Science Educate-it

Minnaertgebouw, Leuvenlaan 4, 3584 CE Utrecht

J.vanWinden@uu.nl 


\begin{abstract}
This article analyzes the design of MasterMind, an escape room that served as a means of professional development in the use and implementation of online educational tools in academic teaching. Escape rooms have inspired educators all over the world to adapt the popular entertainment activity for education. The time-constrained and problem-based games require active and collaborative participants, which makes an escape room an interesting setting for educators. As there are differences in the settings and goals of educational and recreational escape rooms, there is a need for description of the design process, taking into account game design and educational aspects. MasterMind was developed by a multidisciplinary team of educators, educational researchers and game researchers. The design analysis of MasterMind focuses on three related challenges that have informed the design process: 1 ) the participants' transition from the real world to the game world; 2) the alignment of game design aspects and educational aspects in the game world; and 3) the transfer from experiences and knowledge obtained within the game world back into the real world. The description and analysis is guided by frameworks on persuasive games and the alignment of game goals and learning goals. The analysis gives insights in how to balance game and educational aspects in the design, in order for players to reach both persuasive and learning goals. We recommend an integrated approach of the different design challenges. Therefore, we propose a design model combining and aligning the used frameworks, leading to an integrated approach in tackling design challenges in persuasive, serious games.
\end{abstract}

Keywords: educational escape room, persuasive gaming, professional development, alignment 


\section{Introduction}

Escape rooms have inspired educators all over the world to adapt this popular entertainment activity for education purposes. This article discusses the design and design philosophy of MasterMind, an escape room developed at Utrecht University by a multidisciplinary team of educators, educational researchers and game researchers. MasterMind served as a means of professional development in the use and implementation of online educational tools in academic teaching. Its aim was to playfully introduce university teachers to digital educational tools and help them make informed decisions about employing these tools in their educational contexts. It targeted early majority and late majority adopters of digital technologies in education (cf. Rogers, 1962). A majority of the participants perceived that the experience of playing MasterMind made them more inclined to use digital tools in their own teaching, and that it was an enjoyable and meaningful time investment. ${ }^{1}$

This article analyzes the design of MasterMind from the perspective of three design challenges that have informed the design process: 1) the participants' transition from the real world to the game world; 2 ) the alignment of game design and educational aspects within the game world; and 3) the transfer from experiences and knowledge obtained within the game world back into the real world. We argue that educational escape rooms, such as MasterMind, can be positioned in a context of both serious and persuasive gaming and thus need to take into account the design challenges that are particular to both forms of games. Drawing on a general theoretical model for persuasive game design (Visch, Vegt, Anderiesen, \& van der Kooij, 2013) and a design framework for the alignment between game goals and learning goals (Van der Linden, Van Joolingen, \& Meulenbroeks, 2019), the article reflects on how we engaged with the aforementioned challenges in the design of MasterMind. With this, we hope to contribute to the discourse on serious gaming and help foster the dialogue between serious game designers and educators.

\section{Escape rooms in education}

Escape rooms are live-action team-based games in which players encounter challenges that are part of a quest that needs to be completed in a limited amount of time (Nicholson, 2015). Parallel to their immense popularity in the entertainment industry worldwide, escape rooms are gaining popularity as educational environments. Both students and teachers perceive that while participating in escape rooms, students are more engaged and active

\footnotetext{
${ }^{1}$ A post-activity survey was sent to 196 participants. It questioned their experience in the escape room in relation to the goals and their intentions with digital educational tools in their future practice. 127 participants worked as teachers and 38 teachers responded to the survey. Results of a follow up survey to measure actual use of educational tools are still pending.
} 
compared to regular classes (Cain, 2019). The time-constrained and problem-based games require active and collaborative participants, which makes an escape room an interesting setting for educators.

The development of educational escape rooms started bottom-up with enthusiastic teachers. They share materials on platforms, such as Breakout EDU, which has about 40.000 members (Breakout EDU, 2018; Sanchez \& Plumettaz-Sieber, 2019). Educational escape rooms have been developed for a variety of age groups and for various educational purposes: to recruit students (Connelly, Burbach, Kennedy, \& Walters, 2018) or for students to get to know institutional services (Guo \& Goh, 2016). Other case studies describe students developing escape rooms in order to foster design skills (e.g. Li, Chou, Chen, \& Chiu, 2018). Most escape rooms have been designed to foster domain specific skills and knowledge, or to support the development of generic skills and affective goals. Despite increasing scholarly interest in educational escape rooms, there is a paucity of literature on their use in the context of professional development (Fotaris \& Mastoras, 2019). This article aims to address that gap.

\section{Serious games and persuasive games}

Educational escape rooms can be considered a form of serious gaming. Serious game design combines educational design with game design (Lameras et al., 2017; Whitton, 2018). Most research on serious games comprises digital games in educational settings (Ávila-Pesántez, Rivera, \& Alban, 2017; Lameras et al., 2017). Systematic reviews on serious games show a wide diversity in definitions of serious games foregrounding different 'essential' characteristics, such as the role of ICT (Ke, 2016; Lameras et al., 2017). Moreover, authors differ on whether serious games are "games primarily focused on education rather than entertainment" (Miller et al. 2011, p. 1425) or that entertainment and fun come first, as these aspects are considered conditional for learning with serious games (Prenski, 2001; Zyda, 2005). We bypass these differences by following Cook (2005), who offers a broader description of serious games:

“(...) the application of gaming technology, process, and design to the solution of problems faced by businesses and other organizations. Serious games promote the transfer and cross fertilization of game development knowledge and techniques in traditionally non-game markets such as training, product design, sales, marketing, etc."

There are different reasons why non-game markets, of which education is an example, turn to games to solve problems within their organisation. In the case of Utrecht University, games are used to resolve the low acceptance of digital educational tools among staff. The enjoyable and immersive game world can help, motivate, and persuade users to behave in 
ways they experience as difficult in the real world (Visch et al., 2015). Players experience games as not only enjoyable but also protective worlds where actions have fewer consequences than in the real world and can be practiced over and over again (Whitton, 2018). Games can change behavior in the game world and subsequently in the real world. This is the assumption and ultimate aim of persuasive games, a subset of serious games aimed at creating a user experienced game world that changes the user behavior or attitude in the real world (Jacobs, Jansz, \& de la Hera Conde-Pumpido, 2017; Visch et al., 2013). Motivating game elements, such as challenges, draw the player into a game world where equivalents of real world tasks are carried out. The transfer of effects from the game world to the real world can be actively designed, but is often neglected (Visch et al, 2013). How to successfully design this transfer is one of the challenges for developers of persuasive games.

In a review study on digital serious games, Ke (2016) notes that the effectiveness of games created for educational purposes depends on various aspects: 1) the nature of learning to be fostered (skills or conceptual knowledge); 2) how specific game aspects, such as feedback to players, are implemented; and 3) the way games are used in education, for example as a micro-world to embody a situated practice or an interactive, multimodal representation of conceptual knowledge. Ke's findings imply that the specific nature of the knowledge to be obtained and the educational goals to be achieved should primarily drive the design of learning games. Carefully mapping learning actions onto play actions seems to be a necessary and core mechanism for successful learning-play integration, whereas the narrative that structures and frames learning interactions can be considered supplementary. Ideally, the game is designed in a way that players can reach the game goal only by achieving educational goals (Van der Linden et al., 2019). An extra challenge for serious games is to integrate learning and playing without losing what is enjoyable about games (Ke, 2016). In games with poorly developed player experiences, the message is ineffective (Ferrara, 2013). Elements that can help create an enjoyable playful learning environment are puzzles, simulations, role play, humor, surprise, storytelling, and mystery (Whitton, 2018).

Given all these aspects that need to be taken into account, it comes as no surprise that educators "are overwhelmed by the plethora of design choices and level of complexity entailed in integrating, combining and balancing learning with game features" (Lameras et al., 2017, p.990). Lameras et al. (2017) suggest that more dialogue is needed between educators and serious game designers to improve the process of amalgamating learning with gaming. For the design of escape rooms in education, such a dialogue would benefit from more qualitative research that helps understand the concrete considerations and decisions made by developers of educational escape rooms. 


\section{MasterMind: a brief description}

In spite of considerable university investments in technological innovation in education (e.g. licenses, hardware, software, and workshops), a significant part of lecturers at Utrecht University has not yet implemented technological tools in their teaching. These early and late majorities (cf. Rogers, 1962) need to be personally convinced of the value of an innovative technology before investing time in exploring it (Moore, 1991). Moreover, research indicates that this exploration should happen in collaboration with other colleagues and with enough opportunities for reflection (Ertmer, 1999). MasterMind aimed to address this issue with a mobile, pop-up escape room that allows university teachers to experience and engage hands-on with educational technologies in a playful and safe environment, together with others. A post-game debriefing aimed to help participants to reflect on their experiences and make informed decisions about using (or not using) these tools in their own educational setting. Ideally, the positive experience of playing MasterMind contributes to active implementation of digital educational tools in teaching. This is the persuasive goal of MasterMind. MasterMind can be considered an example of persuasive gaming, as it aims to create a user experienced game world to change the teachers' attitudes and behavior in the real world.

MasterMind consisted of two main parts that each lasted one hour: an escape room and a debriefing. The escape room can host 4 to 6 players who sign up as a team. The narrative setting of the escape room is within the fictive tech start-up company MasterMind, founded by student-entrepreneur Tim Turner. Tim has developed 4D Virtual Reality and creates experiences where people can see, taste, feel and smell alternative realities. While waiting for Tim's presentation about MasterMind, the participants are shown a short promo video of the company. Suddenly, Tim breaks into the video signal with an emergency call that he is stuck in his own virtual world. Players will need to get him out, by solving puzzles based on digital educational tools available for teachers at Utrecht University (see figure 1). The puzzles typically consist of a combination of digital and physical activities. Playing the escape room is followed by a one hour debriefing in which a moderator discusses with the team which digital educational tools they have encountered in the game and how these might contribute to the team's teaching practice. The design process of MasterMind was an iterative process, including multiple rounds of play tests with game specialists, educators and the target audience which provided the input for the further development of the escape room. 


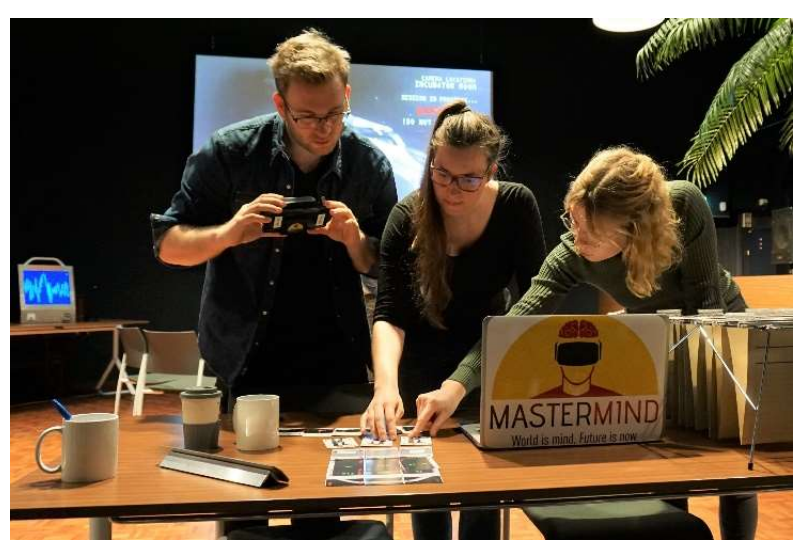

Figure 1: Players in MasterMind working on a puzzle that requires both physical and digital activities.

\section{Design challenges in MasterMind}

In line with our previous discussion on serious games, one of the main challenges in designing the MasterMind escape room was to strike the right balance between game design aspects and educational aspects. More specifically, to design the gameplay in such a way that the game goal (liberate Tim) and learning goal (experience specific digital educational tools) were aligned, without losing the fun and pleasure of the game. Another challenge, in line with MasterMind's persuasive nature, was to successfully transit the participant from the real world (teaching environment) into the game world (Tim's start-up), and finally, to support the transfer of knowledge and experience of the tools obtained within the escape room to the participant's practice of teaching: the persuasive goal In the next section, we will discuss how these three challenges concretely informed the design and design principles of MasterMind, after we have introduced the analytical perspective that frames our analysis.

Figure 2 depicts a design framework that foregrounds the different alignments that need to be taken into account to design a successful educational game (Van der Linden et al., 2019). The framework is developed in line with the intrinsic integration theory, which suggests that the learning goal and game goal should be aligned in an educational game.

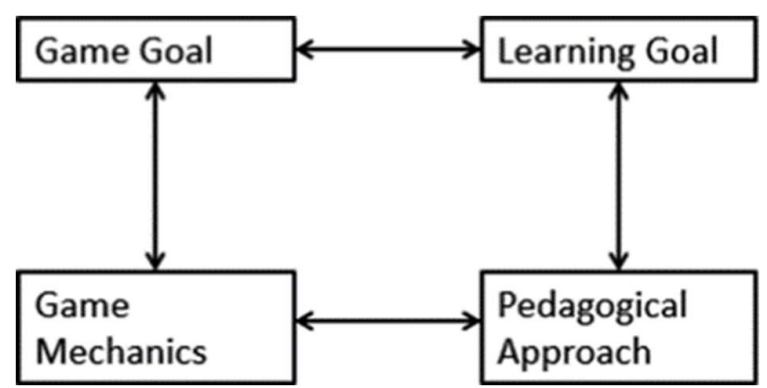

Figure 2: Design framework on alignment between game goal, learning goal, pedagogical approach and game mechanics (Van der Linden et al., 2019). 
Van der Linden et al. (2019) emphasize that the learning goal should be leading in the design of an educational game and that game developers in designing the gameplay need to ensure that the game goal can only be reached when the desired learning goal is reached.

Additionally, according to the logic of alignment, both learning goal and game goal can only be achieved if they are pursued within a matching structure and logic, meaning that the learning goal needs to be supported by the proper pedagogical approach and the game goal by the proper game mechanics. Which pedagogical approach to adopt or which game mechanics to use should be informed by the learning goal and game goal respectively. Moreover, Van der Linden et al. (2019) propose that during the iterations of the design process the focus should be on aligning the pedagogical approach with the game mechanics.

In case of the MasterMind escape room gameplay, the learning goal is for teachers with moderate to low technology acceptance to use a set of digital educational tools and to become aware of their functionalities. To align with this learning goal, MasterMind adopted playful learning as its pedagogical approach, since this aims at an enjoyable, safe environment that offers a positive response to failure and support for learners to immerse themselves in the spirit of play (Whitton, 2018). Within such a safe environment, experiential and collaborative learning can take place to support the learning goal of Mastermind. For the game mechanics to align with this pedagogical approach of playful, experiential and collaborative learning, an integration of the educational tools into the game puzzles and activities is necessary. These puzzles, then, need to steer towards working in a team and having fun. Finally, the gameplay has to be such that only when the toolbased puzzles are solved within time, the game goal can be reached: to liberate Tim from the virtual world.

Figure 3 shows a Persuasive Game Design Model adapted from Visch et al. (2013). The original model is based on three central concepts related to persuasive gaming: gamification, game world and behavioral change design. Persuasive games assume that user behavior and motivations in the real world can be transformed through a process of gamification. In MasterMind the real world is the environment of a university teacher, and the game world is a kick-off meeting for staff at Tim's enterprise. Other than the previous framework, this model does not focus on the game world and game play as much, but describes the players' movement from the real world into the game world and back. 


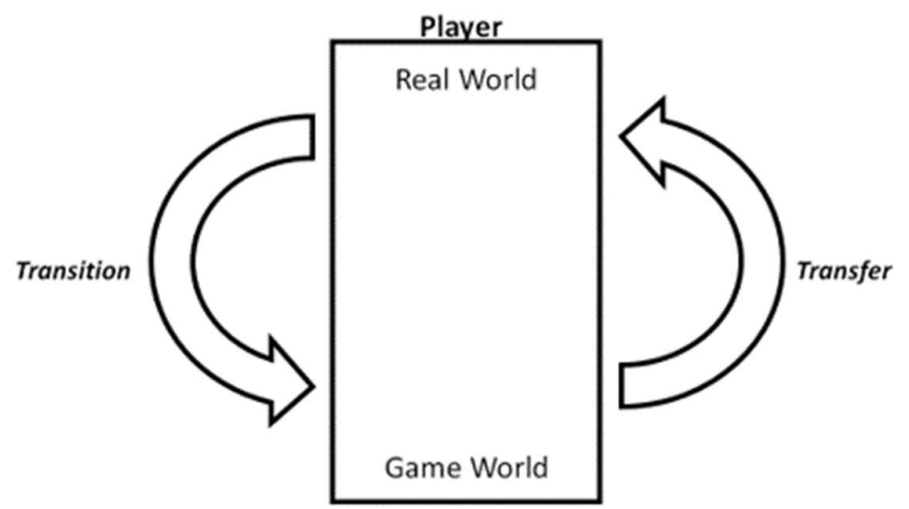

Figure 3: Persuasive game model (adapted from Visch et al., 2013).

According to Visch et al. (2013), for a smooth transition of the player from the real world into the game world, it is important that behavioral and motivational aspects from the real world become part of the game world as what they call 'gamified real-world attributes.' In the game world, these behavioral and motivational aspects can be changed towards the desired behavior or motivation.

If the desired behavior is realized in the game world, Visch et al. (2013) suggest, it can be transferred to the real world and produce a so-called transfer effect: 'the effect of the user experienced game world on forming, altering, or reinforcing user-compliance, -behavior, or attitude, in the real world' (Visch et al., 2013). In order for this effect to take place, the transition from the game world to the real world needs to be designed. This 'transfer design,' the authors claim, is often neglected and formed yet another design challenge for MasterMind. A one hour debriefing session was developed to structure and catalyze this transfer, which included a reflection on the experiences and educational content as conditional for learning with escape rooms (Sanchez \& Plumettaz-Sieber, 2019).

In the following analysis, we describe each part of the Mastermind escape room - pre-game, in-game and post-game - followed by the design considerations in relation to the design challenges. We look into how aspects (behavior, motivation, attributes) of the real world of the participants have been translated into game elements that have been incorporated in the design of the game world (challenge one). We also reflect in more detail on how specific game aspects and educational aspects have been aligned in the design of the MasterMind escape room (challenge two). Additionally, we describe which design strategies MasterMind developed and employed to facilitate a meaningful transfer of experiences, knowledge and ideas obtained within the game world back into the real world (challenge three). 


\section{Pre-game: mailing and welcome}

One week prior to the game, participants received an email from the (fictive) protagonist of the game: student/entrepreneur Tim Turner. He thanks the participant for signing up to the kick-off presentation of his new company MasterMind, shares time and location details and asks participants to be present 10 minutes early. In all communication with the participants, the emphasis was on the narrative, not on the educational goal or pedagogical approach.

On the day of the game, players were welcomed by a game master in a separate informal reception room. Here they found cards with tips for playing an escape room. Meanwhile, the game master walked back and forth between the actual escape room and the reception room, checking if Tim has arrived yet. After a few minutes, the game master invited the players to take a seat in the escape room. He told them that Tim went away to fix a technical issue, but that he is expected to return swiftly, and started a promo-video of Tim's company MasterMind.

\section{Design considerations}

The purpose of the pre-game experience is to facilitate the transition from the real world to the game world and to increase the sense of immersion in the game world and the sense of urgency during gameplay. This is important for the target group, because the game will require them to perform actions and behaviors they do not perform in the real world, namely the hands-on engagement with innovative educational tools.

The in-narrative mailing allows players to relate to the protagonist Tim before the game starts. The contrast of Tim's request to arrive early and him being late is designed to create a tension that might enhance the urge to take action as soon as the game begins. The reception room serves as a transition space, between the real world and the game world. Here, players have the opportunity to leave behind their day-to-day job and get into a playful mood with their team, a familiar strategy in the design of escape rooms (Clare, 2016). The provided tips for how to play an escape room help to boost competitiveness and anticipation for gameplay. This is again designed to increase the urge to take action once the game starts. But more importantly, these tips make implicit game rules and mechanics explicit, preparing players for the game mechanics that will be used. Players that have never played an escape room before will for instance not search the room for clues, unless they understand that this is a regular activity in the game world. Making rules and mechanics explicit might allow for an easier transition from the real world to the game world. 


\section{In-Game: Setting and narrative}

The setting of the escape room was within the fictive tech start-up company MasterMind. There was a lot of equipment with a 1980's look and feel present in the room. The call to action is Tim's cry for help to reset the system to liberate him from the virtual world, which was the game goal.

\section{Design considerations}

To reach our persuasive goal, a balance had to be struck between a setting in the game world that would be out of the ordinary enough for the participants to show out of the ordinary behavior, and a setting that would allow for easy transfer of game attitudes and skills to the professional practice of the participants in the real world. Given the learning goal, the escape room needed to be a technology-rich environment. However, the target group was unlikely to be intrinsically interested in technology and may even be deterred by it. Therefore, the technology that was presented in the narrative (4D virtual reality) is obviously science fiction. Through their 1980's look and feel, all the physical equipment made it obvious that this is not something the players have to worry about in daily life while it created an acceptable environment to work with technology.

A student was chosen as protagonist, introducing him in the mailing and promo video as someone teachers can relate to. The call to action is urgent, confronting teachers with a challenge they have never had at hand before, making it sensible that new types of solutions and behaviors are needed to solve this problem. On the other hand, helping a student with a problem does align well with the professional practice and real world roles of the players, allowing for an easier transfer. This is in line with the situated learning theory, which states that learning should take place in a practice in which it would normally be applied (Lave \& Wenger, 1991).

\section{In-Game: social design}

The escape room aimed at facilitating teacher teams. Players share the same experience during the start and the end of the game. In mid-game, several puzzles were open to work on synchronously. Most teams split up to work in pairs on these puzzles, with pairs helping each other when needed.

\section{Design considerations}

Ertmer (1999) identifies collaboration as an important strategy to address teachers' reluctance to use technology in education. This was part of our pedagogical approach. 
During the game, collaboration between players was needed to solve the puzzles, mirroring the help teachers can get within their own immediate working environment.

\section{In-Game: Puzzles}

The escape room introduced the teachers to seven educational tools they could use in their own teaching. The actual tools were used in the puzzles, no simulations or mockup versions. Puzzles typically consisted of a combination of digital and physical activities. The physical activities were most of the time primarily designed for fun and engagement while the digital activities emphasized the learning goal of the escape room (to use a set of digital tools and become aware of their functionalities).

\section{Design considerations}

The selection of the tools was informed by their availability within the real world. All tools were supported by Utrecht University. Moreover they were selected to cover a variety of educational functions. Implementing the actual tools in the game design allowed players to experience the real product, but this limited possibilities in designing the puzzles. Practical matters were also taken into account, such as the possibility to adapt the tool to design puzzles and the ability to quickly reset the tool for the next group of players. Although most tools required only digital activities to engage with their functionalities, physical activities were added in the design for a number of reasons: to appeal to this specific target group of teachers belonging to the early and late majority, to link the digital activities in the narrative, to stimulate interaction between players, and to stimulate fun, immersion and diversity in activities.

The tool-based puzzles closely followed functions and procedures that participants could use in their own teaching. One puzzle, for instance, was aimed at engaging with a tool for practicing communication skills, using video assignments. First, players needed to find a spoken password in a physical puzzle, then they received instructions in the educational tool on how to speak to convince people and machines. The next step was to practice this skill by recording a video in the educational tool. After doing this, they received feedback on their performance within the tool, just as students would. They subsequently had to apply this feedback on the found password and unlock a physical machine by saying a piece of text in a specific manner in a microphone. Then, a physical reward in the form of a code is unlocked.

Altogether, this puzzle allowed teachers to experience how students can receive instruction, practice communication skills, and receive feedback in this platform and then apply the learned skills in practice. So, in order to reach the game sub-goal (the unlocked code), 
players should also meet the learning sub-goal (using the specific educational tool and discovering its functionalities).

The last puzzle of the escape room was designed as a team activity with all players standing around a table. Because it was the last puzzle and not all teams would be able to finish it, this puzzle was not directly linked to one of the learning goals for the escape room. However, it did contribute to the escape room being a shared experience and facilitated group discussions during the post-game debriefing.

\section{Post-Game}

The game ended when Tim had been liberated from the virtual world or when 60 minutes had passed. The success rate of players was about $60 \%$. A specific video started, depending on the outcome (i.e. whether Tim was released or not). When the teachers succeeded in their mission, Tim showed his gratitude. When players did not succeed, Tim is set on a tropical island, saying that life in virtual reality is not so bad after all. Then it was time for the team photo, taken with a cardboard version of Tim.

After some time to cool down and share game play experiences, the debriefing took place in the reception room, linking the player experiences to teacher experiences. For each puzzle, the players who were most involved in that part of the escape room explained the puzzle (gameplay) and what they thought was the educational potential of the tool for their teaching practice. The facilitator could add his expertise and experience with the tools to the discussion. After all tools had been discussed, participants brainstormed about applying the tools for their own teaching. Technical and educational support were offered to teachers who liked to implement some tools or practices, and follow-up actions were able to be planned.

\section{Design considerations}

The first moments after gameplay were designed to evoke positive emotions to increase the odds that players are open to reflection with regards to their own teaching practices during the debriefing. For most players, the escape room was a challenging activity, leading to a sense of fulfillment and joy when they succeeded in their mission to rescue Tim. However, when players fail, these positive emotions were not triggered. As a solution, we chose to offer comic relief by illustrating that Tim is happy in his new surroundings in the virtual world. For both endings, the cardboard version of Tim had a different function. For the successful teams, it functioned as a reward to be able to take a picture with Tim, the student they saved. For players that failed, again this is an object for comic relief: "Since Tim is virtualized, he couldn't make it to take a picture with you, but we did print a cardboard 
version for you." The team photo is an almost ritualistic part of most escape rooms. It makes explicit that - whether successful or not - the endeavor was a team effort, emphasizing the shared experience.

After a few minutes, all players moved over to the reception room for the debriefing. Again, the reception room functioned as a transition space, this time between the game world and the real world. The debriefing was designed to facilitate a shared reflection on the experiences with educational tools during gameplay, considering reflection is a key strategy for technology acceptance among teachers (Ertmer, 1999). During the debriefing, the individual player experiences of different puzzles were shared. The conversation was steered from player experience to teacher practice by the facilitator for each puzzle and thereby each tool. The debriefing ended with focusing entirely on applications in the real world and follow-up actions to support teachers in their practice.

\section{Conclusion}

In this article we analyzed the design of the educational escape room MasterMind with a specific focus on three challenges that have informed the design process: 1) the participants' transition from the real world to the game world; 2 ) the alignment of game design aspects and educational aspects in the game world; and 3) the transfer from experiences and knowledge obtained within the game world back into the real world. In our analysis of the design, we have demonstrated that these challenges are inextricably linked to one another and call for an integrated design approach, especially when the educational escape room does not only aim for learning goals, but a persuasive goal as well. This is even more crucial if the target group are early and late majorities in professional development, who need to be personally convinced of the value of an innovative technology before adopting it. This article adds to the studies on educational escape rooms in that it shows the importance of paying as much attention to the design of the game play - making sure that the learning goal during gameplay is achieved - as to the transfer of the learned behavior into the real world to achieve the persuasive goal. 


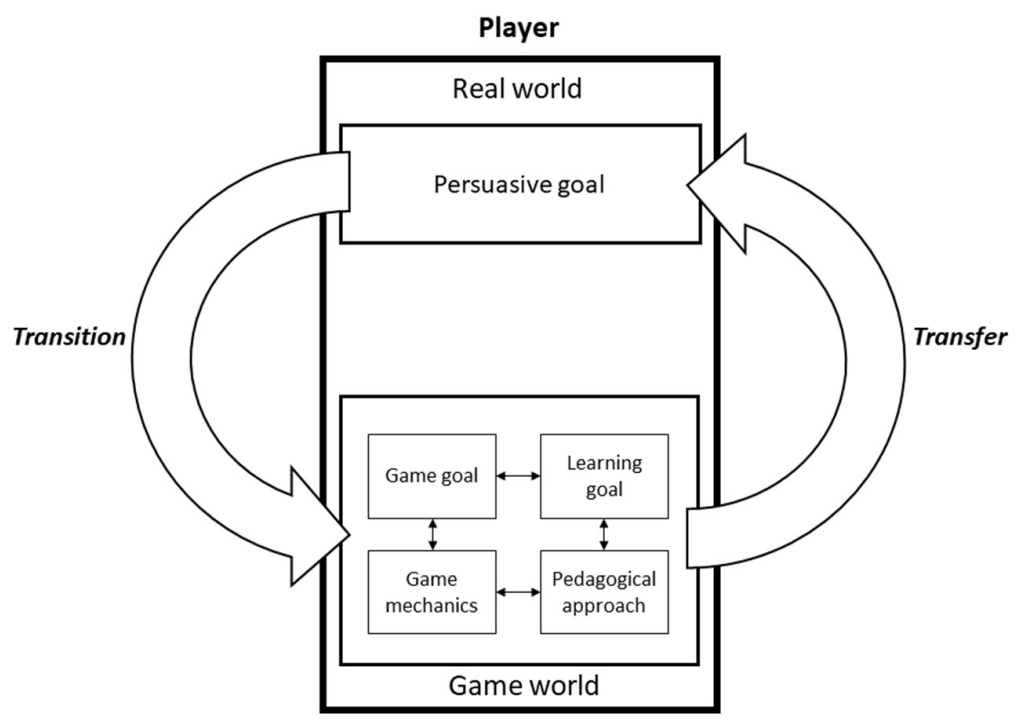

Figure 4: Integrated design approach for educational escape rooms

We propose an integrated framework (see figure 4) that can help designers to focus on alignment in tackling the main design challenges in persuasive games. The overarching persuasive goal starts the loop, steering the alignment of the design processes of gamification, gameplay and transfer. We believe that future educational escape rooms will be more persuasive in attaining their goal, when pre-game, gameplay, as well as post-game design are all driven by the same persuasive goal and learning goal and game goal are properly aligned within the game design.

\section{Acknowledgments}

The project was funded by the Utrecht University Education Incentive Fund and Utrecht University's educational innovation program Educate-it.

\section{Statements on ethics}

There are no conflicts of interest to disclose.

\section{References}

Ávila-Pesántez, D., Rivera, L. A., \& Alban, M. S. (2017). Approaches for serious game design: A systematic literature review. The ASEE Computers in Education (CoED) Journal, 8(3). 
Breakout EDU. (2020, February). Retrieved February 24, 2020, from http://www.breakoutedu.com/.

Cain, J. (2019). Exploratory implementation of a blended format escape room in a large enrollment pharmacy management class. Currents in Pharmacy Teaching and Learning, 11(1), 44-50.

Clare, A. (2016). Escape the Game: How to make puzzles and escape rooms. Toronto, Canada: Wero Creative Press.

Connelly, L., Burbach, B. E., Kennedy, C., \& Walters, L. (2018). Escape room recruitment event: Description and lessons learned. Journal of Nursing Education, 57(3), 184-187.

Cook, D. (2005, May 14). Serious Games: A broader definition.

https://lostgarden.home.blog/2005/05/14/serious-games-a-broader-definition/

Ertmer, P.A. (1999). Addressing first- and second order barriers to change: Strategies for technology integration. Educational Technology Research and Development, 47(4), 47-61.

Ferrara, J. (2013). Games for persuasion: Argumentation, procedurality, and the lie of gamification. Games and Culture, 8(4), 289-304.

Fotaris, P., \& Mastoras, T. (2019, October). Escape rooms for learning: A systematic review. In ECGBL 2019 13th European Conference on Game-Based Learning (p. 235 -244 ). Sonning Common, UK: Academic Conferences and publishing limited.

Guo, Y. R., \& Goh, D. H. L. (2016). Library escape: User-centered design of an information literacy game. The Library Quarterly, 86(3), 330-355.

Jacobs, R. S., Jansz, J., \& de la Hera Conde-Pumpido, T. (2017). The key features of persuasive games: A model and case analysis. In R. Kowert \& T. Quandt (Eds.), New perspectives on the social aspects of digital gaming: Multiplayer (Vol. 2, pp. 153-171). New York: Routledge.

Ke, F. (2016). Designing and integrating purposeful learning in game play: A systematic review. Educational Technology Research and Development, 64(2), 219-244.

Lameras, P., Arnab, S., Dunwell, I., Stewart, C., Clarke, S., \& Petridis, P. (2017). Essential features of serious games design in higher education: Linking learning attributes to game mechanics. British journal of educational technology, 48(4), 972-994.

Lave, J., \& Wenger, E. (1991). Situated learning: Legitimate peripheral participation. Cambridge, UK: Cambridge University Press. https://doi.org/10.1017/CBO9780511815355

Li, P. Y., Chou, Y. K., Chen, Y. J., \& Chiu, R. S. (2018). Problem-based Learning (PBL) in interactive design: A case study of escape the room puzzle design. 2018 1st IEEE 
International Conference on Knowledge Innovation and Invention (ICKII), 250-253. https://doi.org/10.1109/ICKII.2018.8569131

Miller, L. M., Chang, C. I., Wang, S., Beier, M. E., \& Klisch, Y. (2011). Learning and motivational impacts of a multimedia science game. Computers \& Education, 57(1), 14251433.

Moore, G. A. (1991). Crossing the chasm: Marketing and selling technology products to mainstream customers (1st ed.). New York, NY: HarperBusiness.

Nicholson, S. (2015). Peeking behind the locked door: A survey of escape room facilities. Retrieved February 14, 2017, from http://scottnicholson.com/pubs/erfacwhite.pdf

Prensky, M. (2001). Digital game-based learning. Computers in Entertainment (CIE), 1(1), 2121.

Rogers, E. M. (1962). Diffusion of innovations (1st ed.). New York, NY: Free Press of Glencoe.

Sanchez, E., \& Plumettaz-Sieber, M. (2019). Teaching and Learning with Escape Games from Debriefing to Institutionalization of Knowledge. In M. Gentile, M. Allegra, \& H. Söbke (Eds.), Games and Learning Alliance, Lecture notes in computer science vol. 11385 (pp. 242-253). Cham: Springer.

Van der Linden, A., Van Joolingen, W. R. \& Meulenbroeks, R. F. G. (2019). Designing an intrinsically integrated educational game on newtonian mechanics. In M. Gentile, M. Allegra, \& H. Söbke (Eds.), Games and Learning Alliance, Lecture notes in computer science vol. 11385 (pp. 123-133). Cham: Springer. https://doi.org/10.1007/978-3-030-11548-7

Visch, V.T., Vegt, N.J.H., Anderiesen, H., van der Kooij, K., (2013, April). Persuasive Game Design: A model and its definitions. Paper presented at CHI 2013: Workshop Designing Gamification: Creating Gameful and Playful Experiences, Paris, France. Retrieved from https://www.narcis.nl/publication/RecordID/oai:tudelft.nl:uuid\%3A23ad5ef4-fbf3-4e9c8815-1edf9da40456

Whitton, N. (2018). Playful learning: Tools, techniques, and tactics. Research in Learning Technology, 26.

Zyda, M. (2005). From visual simulation to virtual reality to games. Computer, 38(9), 25-32. 